\title{
Configuring robot work cell based on a multi-shaped layout approach
}

\author{
N. S. Osman', M. A. A. Rahman ${ }^{1 *}$, A. A. Abdul Rahman ${ }^{1}$, S. H. Kamsani ${ }^{1}$, \\ E. Mohamad', B. M. B. Mohamad' ${ }^{1}$ Z. A. Zaini' ${ }^{2}$ and M. F. A. Rahman' \\ ${ }^{1}$ Integrated Manufacturing Systems (I'Ms) Research Group, \\ Advanced Manufacturing Centre, Faculty of Manufacturing Engineering, \\ Universiti Teknikal Malaysia Melaka, Hang Tuah Jaya, 76100 Melaka, Malaysia \\ Email:*arfauz@utem.edu.my \\ Phone: +606-3316488 \\ ${ }^{2}$ Department of Occupational Safety and Health, Aras 2, 3 \& 4, \\ Blok D3, Kompleks D, Pusat Pentadbiran Kerajaan Persekutuan \\ 62530 W. P. Putrajaya, Malaysia
}

\begin{abstract}
This paper describes developmental work on a multi-shaped layout approach for configuring robot work cells in the future. The idea is to configure robot work cells based on the total number of robots and its variations of layouts. At present, the multi-shaped layout of robot work cells is developed by joining two or more robot work cells in the form of a square-shaped layout based on several constraints and conditions. Data on the probable multi-shaped layouts of robot work cells have been tabulated, and the complexity of data for each configuration was compared. Afterward, the configuration with the least complexity was selected to be the optimum configuration concept. As a result, a configuration pattern with a mathematical relation between the number of robots and the number of possible multi-shaped layouts was able to be extracted using MATLAB. The details regarding the development phases of this work are presented. The primary purpose of this work is to provide a configuration concept of robot work cells for assisting system design engineers in configuring robot work cells which could enhance configuration time, minimise human and expert involvement, and capitalise available investment resources in future. This developmental outcome is relevant for inline configurations of robot work cells. The currentoutcomes of this work provide a basic concept for future investigation on developing a flexible configuration system for multiple robot work cells.
\end{abstract}

Keywords: Industrial robot; multi shape; configuration; reconfigurable and flexible manufacturing system.

\section{INTRODUCTION}

Globalisation has created a new environment where all manufacturing competitors around the world have similar opportunities [1-4]. Consequently, competition happens even though competitors that produce similar products are located in different parts of the world [5]. Particular attention on the productivity and quality of products are given in order to satisfy customer demands [6,7]. As the result, there is the need for automated manufacturing as a resolution to this type of environment. Due to the fast development of manufacturing automation, the demand for industrial robots is growing annually [8]. In 
the latest statistic as presented in Figure 1 which was issued by the International Federation of Robotics (IFR) in its 2015 World Robotics report, the utilisation of industrial robots in the manufacturing industry has shown to increase from 2013 to 2016. Following the current trends, they predicted that by 2018, global sales of industrial robots will grow by at least $15 \%$ yearly on average [9].

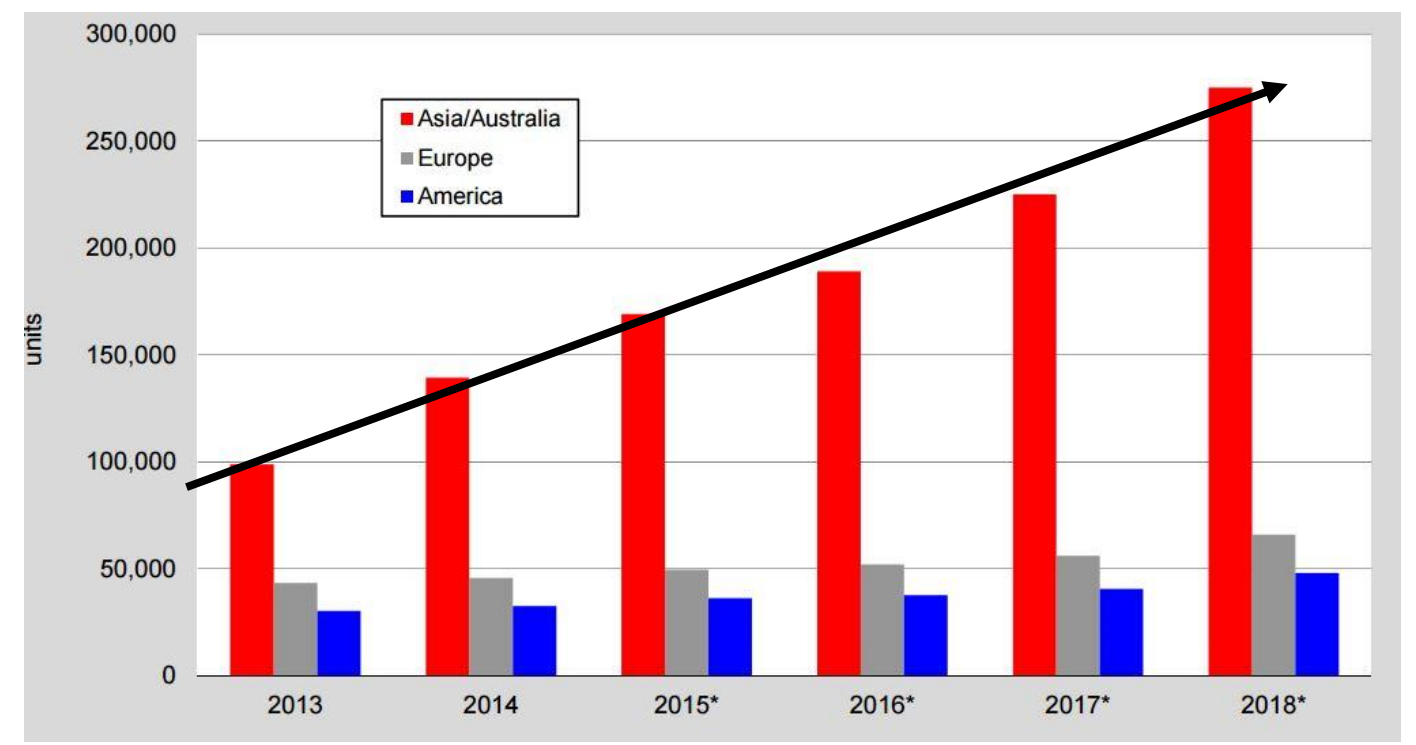

Figure 1. Worldwide Annual Supply of Industrial Robots [9].

The continuous increase of industrial robot utilisation has led the industry to face a new challenge in (re-)configuring their current robot work cells, as well as their future cells appropriately [10]. Furthermore, the current market situation is unpredictable and rapidly changes depending on customer demands [10-14], thus also contributing to the challenge in the configuration process. Configuration is important because it gives a profound impact on the performance of a system; not only on its adaptability to market demands, but also on its reliability, productivity, product quality, and cost. Thus, it is important to understand the impact of the proper selection of robot cell configurations for optimal performance [11]. Based on the common configuration approach, configuring robot work cells requires high costs in terms of investment, commissioning time, level of expert knowledge and human involvement [10, 13, 15-22]. Therefore, the development of a configuration concept has occurred to develop a flexible configuration system in the future which could solve the recent emergence of configuration challenges. In this study, we present a literature review of the different studies which had undertaken robot work cell configuration, and also present the development in the design of the configuration concept. The proposed configuration concept may assist system design engineers in (reconfiguring robot work cells and improve configuration time, optimise humans' and expert involvement, and capitalise on the available resources for future investments.

\section{Overall Robot Work Cell Configuration}

There are only a few studies conducted on the modelling of robot work cells which can be reviewed and used for this research. One of the studies was carried out in [23]. They investigated the problem related to the 2-D layout of single and the multiple-robot cells, along with numerous cell configurations. Thereafter, they proposed a conceptual process for the modelling of a novel layout requirement for restricted problems related to the fixed 
positioning of moving-arm robots. Afterwards, in [24], a study was conducted on the designing and positioning of a robot in an environment with obstacles. This work intended to propose a suitable design and position for a robot by considering it as a minimisation problem of the non-attained space in the target landscape. The optimisation variables used in this work were the robot's position, orientation and the Denavit-Hartenberg's parameters. Further improvement is needed to make their work capable for the designing and positioning of more than one robot.

And in [25], a method for deciding a robot layout has been patented. They invented a method in which the range of a robot's motions is displayed and the layout of the robot is decided upon investigating the interference with obstacles and the robot capability to perform motions on a workpiece. Their method which had focused on a single robot provides a basic idea in configuring robot work cells. In addition, [6] offered an automated planning of a robot work cell layout to enhance the conventional layout planning process and reduce the necessity of user interaction by using the layout planning algorithm. The planning algorithm uses a cube-space and a Cartesian configuration-space. Together with the developed layout, suitable collision-free trajectories are generated. Future improvement of this study could include widening and optimising the layout planning concept for multiple robots.

[26] presented a paper which described a heuristic algorithm for optimising the layout of a robot. The heuristic algorithm is intended to minimise the entire path of travel of a robot arm for a given sequence of operations by determining the relative positions and orientations of the stations in the work cell. Indirectly, this research had managed to minimise the cycle time of a robot work cell and hence, improved its productivity. Further improvements suggested for this work include making it applicable on more than one robot. Additionally, another configuration work in [27] has been found where an algorithm for deciding the optimal location of a robotic manipulator inside a work cell for the least time of composed movement was proposed. The algorithm utilises a simple principle of coordinated motion to gauge the time of a joint interpolated motion. The outcomes of the robot optimal placement could improve the cycle time of a robotic operation by as much as $25 \%$. Yet, future work is needed in modelling or testing the algorithms for the cooperation of multiple robots. Besides that, [28] had aimed to design a compact work cell (spatial requirement) and minimise the task completion time (temporal requirement). This work had intended to achieve a high throughput with minimal work cell space. They showed the effectiveness of the proposed method through simulations. However, further study on optimisation is needed, especially from the safety aspect. Also, [29] presented an optimal placement for defined tasks in a robotic manipulator workspace. They applied the response surface methodology for path translation and path rotation. Based on their approach, the authors also developed a robotic optimisation tool as an add-in to RobotStudio. Their method was verified properly by optimising the positioning of industrial robots and their paths in 4 different showcases to attain minimal cycle time.

Additionally, [30] presented work on the optimisation of multi-robot work cell layout in a vertical section plane which was used to manufacture the outer surface of a large fuselage panel. The purpose of this work was to maximize the overlapped workspace of two robots without having a collision between the robots and work pieces. This approach was able to achieve a layout that yielded reasonable positions for two robots, and it was tested on an existing layout. However, this work can only be used on two robots only. In another study [31], a process and system for the optimisation of different workstation positions in an industrial robot work cell was presented. In this 
work, a system and optimisation process for the work cell layout included one or many tasks, and the industrial robot used for carrying out these tasks was tested. Their work had aimed to improve the robot performance and improve the robotic work cell productivity. Next, a unique layout approach was proposed using the Differential Evolution (DE) for solving the Facility Layout Planning (FLP). The robotic work cell layout was one FLP example that was described in this report. The mathematical FLP model is subjected to many constraints, thus the optimisation objective was proposed and the digital simulation platform in the case of an automated layout optimisation was developed to accomplish a 3-D visualisation demonstration of the optimal layout [32]. Moreover, [33] proposed a new approach for the simultaneous design of multi-robot cells for spot welding and the generation of related robot motions. This method intends to present a radical change in the traditional way of solving problems. The problems addressed in this work were; (a) reduction in design time and cell installation time, (b) homogeneity of provided solutions due to the high formalisation granted by the approach, (c) high independence from operator's skill and knowledge, and (d) better ability to explain operated choices to final client. However, this work needs to optimize cell design and motion planning. An optimal robot placement for task execution was introduced in [34] to optimise the base position of an industrial robot with the objective to reach all predefined tasks and minimise cycle time. They also integrated the robotinverse kinematics and collision avoidance using a derivative-free optimisation algorithm. This approach had successfully provided a feasible solution in improving the cycle time of a robot station by placing the robot in an optimal position. However, ongoing work needs to focus on the optimisation of several robot placement and on the automatic creation of optimised robot programs. Another configuration work was introduced in [16] where the FraRWCC framework for determining the workspace and safe working area of the robot was proposed. The purpose of their work is to provide a fast and simple configuration method for a safe robot working area. The developed framework is capable of presenting 3D simulation of a robot work cell, but it is only concentrated on linear (straight) arrangements and for up to four robots.

\section{Issues on the Future Improvement of Earlier Works}

From the research reviewed, it is clear that various configuration methods have been proposed. However, many issues have arisen and need to be taken into account in order to make further improvements in the future. The raised issues are the configuration time $[24,26,30,34]$, human involvement $[6,24,26,28,30]$ and some other investments like workspace, costs, or automatic creation $[23,25,29,32,33,35]$. In this work, we propose a robot work cell configuration concept which is simple and easy to understand by end users. The needed level of expertise to deal with the configuration concept is also optimised. Additionally, we created a configuration concept which involves up to ten robots and include safety measures. We also intend to provide robot work cell configuration information to design engineers as it can maybe assist in improving future configuration time and optimising future investment.

\section{METHODS AND MATERIALS}

\section{Development of Configuration Design}

Figure 2 shows a flow chart that summarises the overall development of the multi-shaped layout approach used in configuring the robot work cell. Basically, it comprises of three phases which are framework design, constraint definition, and framework development. The framework design of a multi-shaped layout begins with the identification of shape 
and safety area of the robot work cell. Afterwards, the development of the multi-shaped layout approach is continued by defining the framework constraints and conditions. Lastly, the framework of the robot work cell's configuration is developed. The multishaped layout is formed by joining one or more single robot work cells in the form of equal squares side by side according to the quantity of robots used. The number of possible multi-shaped layouts is calculated and tabulated to represent the pattern with the respective number of robots used for four different configurations. The results of the configurations were compared and the configuration with the least complexity presentation will be selected. In this phase, a polyominoes study in [34]is taken as a reference due to its use as an identical design concept. Afterward, the configuration pattern and its mathematical relationship are extracted using MATLAB.

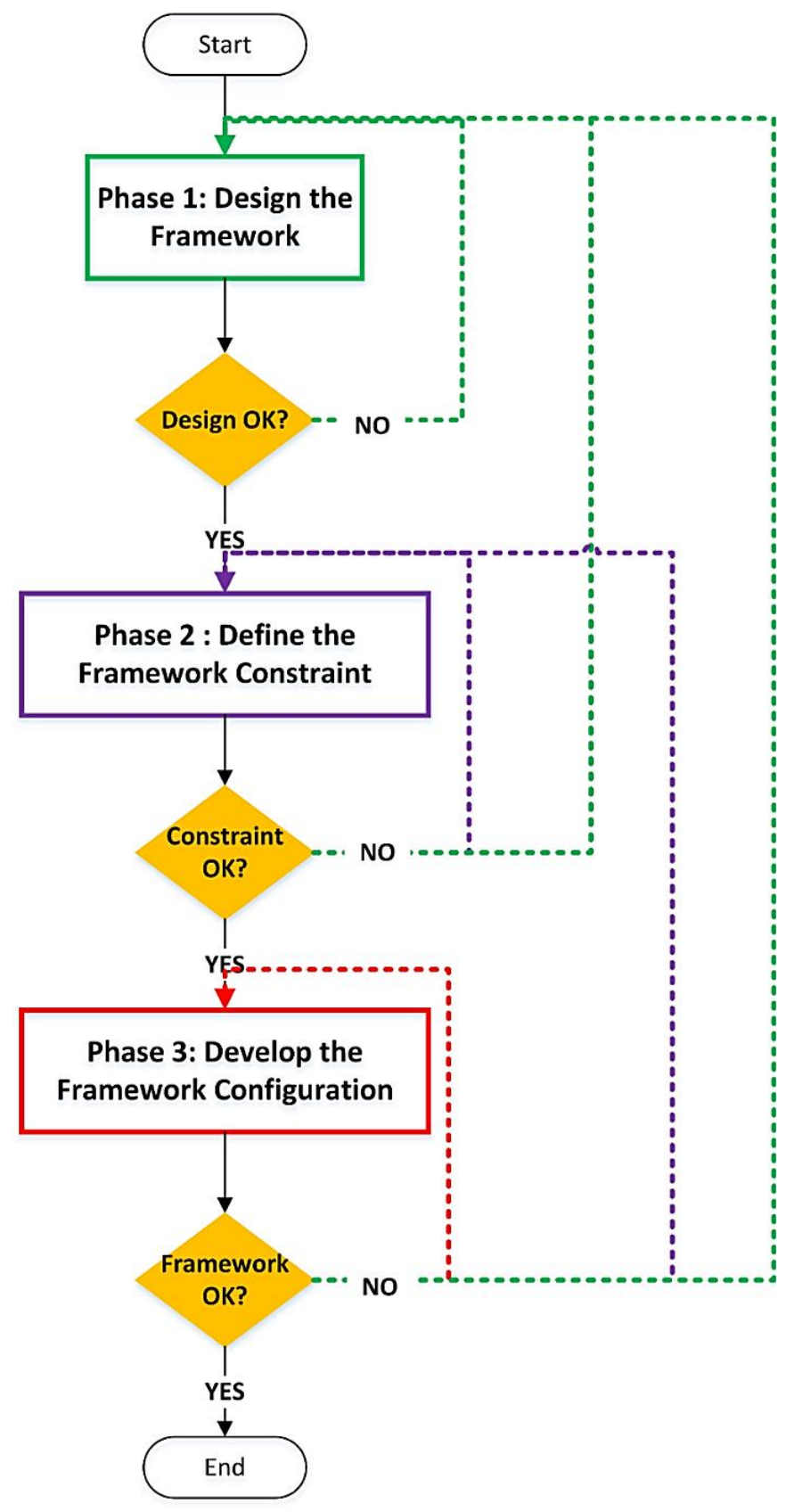

Figure 2. Overall design development 


\section{Identification of Robot Work Cell}

The workspace of an industrial robot must be taken into consideration in the formation of an industrial robot work cell configuration. Workspace refers to the reachable areas where the industrial robot can move and work within a safe zone. The size of the workspace determines the boundaries of reach and the safety area for human workers to enter while performing tasks [36]. Figure 3 represents the 2D workspace of a single robot layout with its safety measure which is used in this work. This is considered as a square-shaped layout. For the general representation of a robot work cell, an articulated robot is taken as reference because it is one of the most widely used robots in many industries. In addition, only two auxiliary equipment are considered in this representation which are robot tooling and work piece. The formula developed by [37] serves as the basic idea for the safety measure of the robot work cell, where it is the key to the formulation of a multi-shaped robot work cell and its configuration pattern. In addition, it will help users to determine the overall safe working area, $\mathrm{A}_{\text {safe }}$ of the desired layout during installation.

$$
L_{\text {safe }}(L)=2(X+Y)+2 C
$$

\section{where $X$ : Length of robot arm $(\mathrm{mm})$ \\ $Y$ : Length of the robot tooling and work piece $(\mathrm{mm})$ \\ $C$ : Clearance for the worker movement in a work cell $(\mathrm{mm})$}

$$
\begin{aligned}
A_{\text {safe }} & =L_{\text {xsafe }} \times L_{\text {ysafe }} \\
& =2(X+Y+C) \times 2(X+Y+C)
\end{aligned}
$$

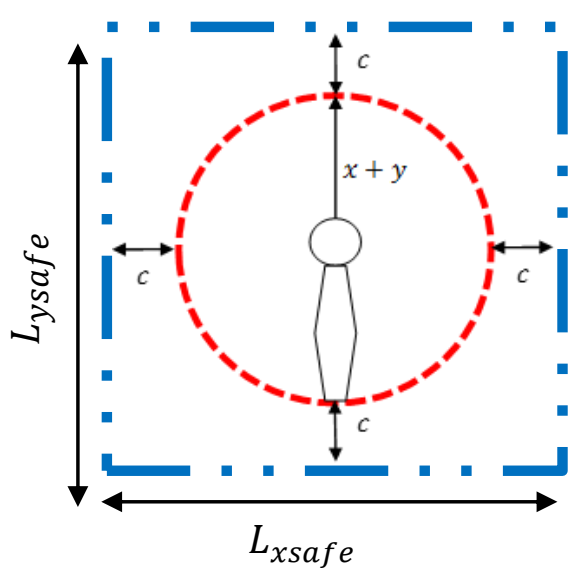

Figure 3. Basic Illustration of a Safe Robot Work Cell for a Single Robot

\section{Determination of Configuration Constraints}

To provide a reliable solution to this work, the following constraints are taken into account:

\section{A. Complex Conditions}

From the preliminary case study of this work, complex conditions are identified by joining two robot work cells in the form of a square-shaped layout in various perspectives. Complex arrangements of robot work cell layouts are not considered in this work due to the difficulty in examining the trend of robot work cell configuration. Complex 
arrangements may refer to arrangements in the form of the perspectives presented in Table 1.

Table 1. Complex arrangement perspectives.

\begin{tabular}{l} 
Num. Arrangement Shape \\
\hline 1. Corner arrangement \\
The corner arrangement refers to the \\
positioning of robot work cells by joining \\
the edge of a robot work cell with the edge \\
of another robot work cell.
\end{tabular}

2. Half facing arrangement

The half facing arrangement refers to the positioning of a robot work cell by facing half of the length of two robot work cells to each other. In other words, the upper half of one robot work cell will face the bottom half of the other robot work cell.

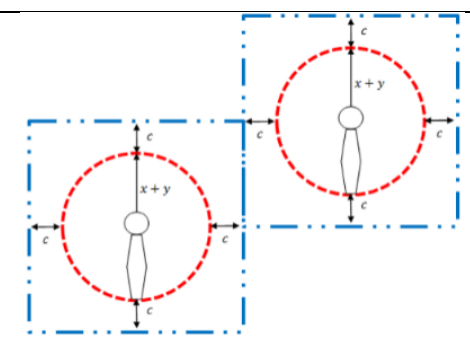

3. Diagonal arrangement

The diagonal arrangement refers to the positioning of two joined robot work cells in a sloping pose. The angle of the sloping pose is between 1 to 89 degrees.

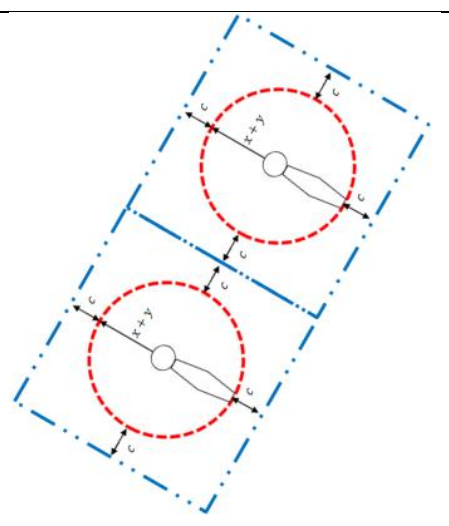

4. Mix-arrangement

Mix-arrangement refers to the positioning of robot work cells by joining one robot work cell linearly to a slanted robot work cell.

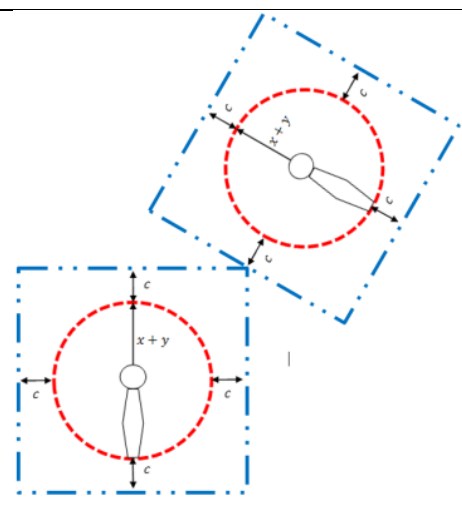




\section{B. Number of Robots Used, $N_{r}$}

Another consideration is the limitation on the number of industrial robots working within a work cell. For the purpose of this work, a maximum cap was put on ten industrial robots. The ten industrial robots are sufficient to form patterns of robot work cell configurations.

\section{Auxiliary Equipment}

For this work, only two auxiliary equipment are considered in the robot work cell layout which are robot tooling and work piece.

\section{Design of Configuration Conditions}

The configuration is developed in a simple linear arrangement. The general configuration consists of a plane geometric figure formed by joining one or more equal squares side by side. It is a poly form whose cells are squares. Two conditions are taken into account in this configuring work which is dual- and mirror- conditions. In the early stage of the condition representation, one robot work cell is used as reference. The detailed description is discussed below.

\section{A. Dual Condition}

A dual condition is represented as one of the layout conditions that may be viewed from either the horizontal or vertical perspective. It presents the same shape layout but with different orientations.

1. The horizontal layout can be defined as a display of an assortment of breadth by rows and an assortment of depth by columns conversely, while

2. The vertical layout can be defined as a display of an assortment of depth by rows and an assortment of breadths by column.
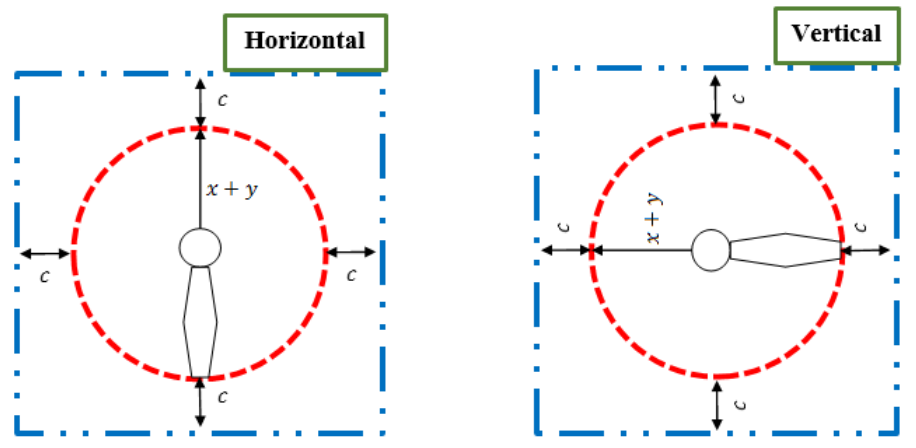

Figure 4. Dual Condition

\section{B. Mirror Condition}

A mirror condition is a transformation where a layout is reflected across a straight line ( $x$-axis and $y$-axis), thus creating a mirror layout. The angle of reflection is $180^{\circ}$. The reflection over an axis will result in two similar shape layouts with different coordinates. Reflection over $\mathrm{x}$-axis: $\mathrm{T}(\mathrm{x}, \mathrm{y})=(\mathrm{x},-\mathrm{y})$ Reflection over $y$-axis: $T(x, y)=(-x, y)$ 


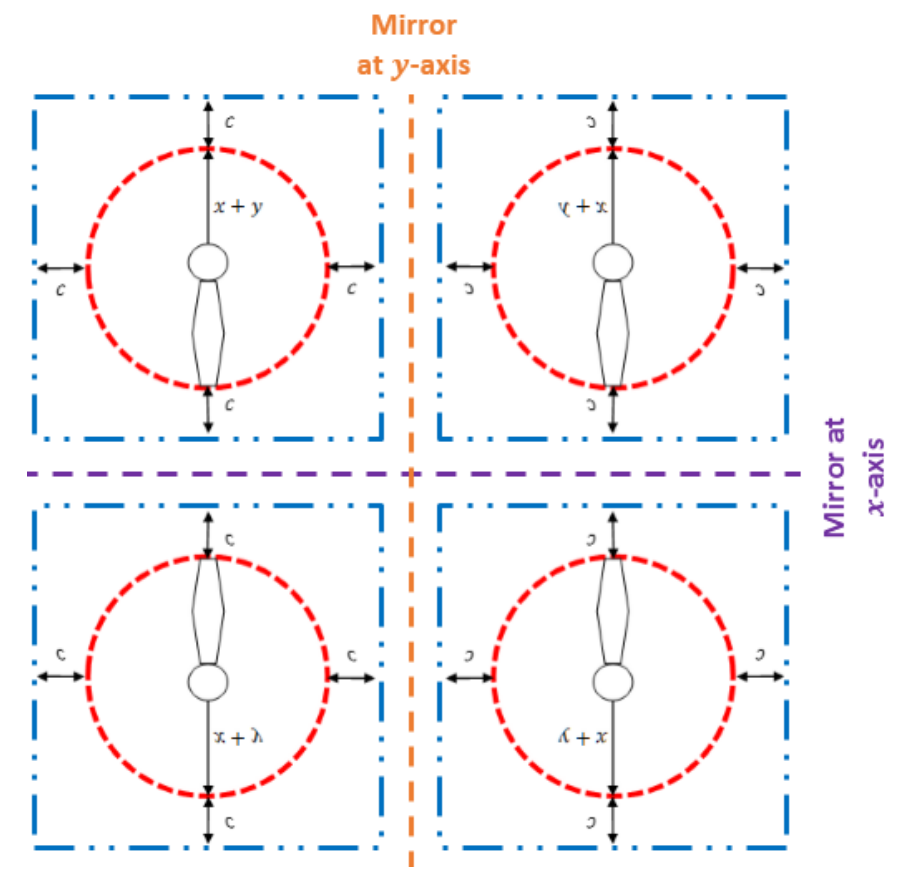

Figure 5. Mirror condition.

With the presence of these two conditions, four different configurations were examined, and the complexity was compared and analyzed. The configurations are:

A. Configuration with both dual and mirror conditions, $C_{1}$

B. Configuration without dual and with mirror condition, $C_{2}$

C. Configuration with dual and without mirror condition, $C_{3}$

D. Configuration without both dual and mirror conditions, $C_{4}$

\section{RESULTS AND DISCUSSION}

\section{Multi-Shaped Layout}

The proposed approach was adopted to design 2D robot work cells according to the quantity of robots used. Table 2 represents all possible layouts that use up to two robots. The purpose of presenting only two industrial robots is to give an overview of the available configurations. Later on, data of possible robot work cell layouts for up to ten robots will be presented. At this stage, a polyominoes study in [35]

[38] was taken as reference as it provides the same design approach as this work. Polyominoes refer to the figures formed using the congruent squares placed so that the squares share a side.

A. Condition 1: Configuration with Both Dual and Mirror Conditions, $C_{1}$.

Table 2 illustrates the linear arrangements of robot work cell layouts for the configuration of both dual and mirror conditions. The robot work cell layouts are developed separately for the dual condition (horizontal and vertical). Meanwhile, for the mirror condition, the robot work cell layout can be developed using both the $x$ axis and $y$-axis in the same figure. From the above figure, it can be concluded that a layout can be drawn into another two layouts in the form of horizontal and vertical conditions, while each of it can be drawn into another four layouts using the mirror condition. To sum up, the usage of one robot is possible to create another eight robot 
work cell layouts, while by using two robots, it is possible to create another eight layouts using the two conditions.

Table 2. Multi-Shape Designed Layout with Condition 1

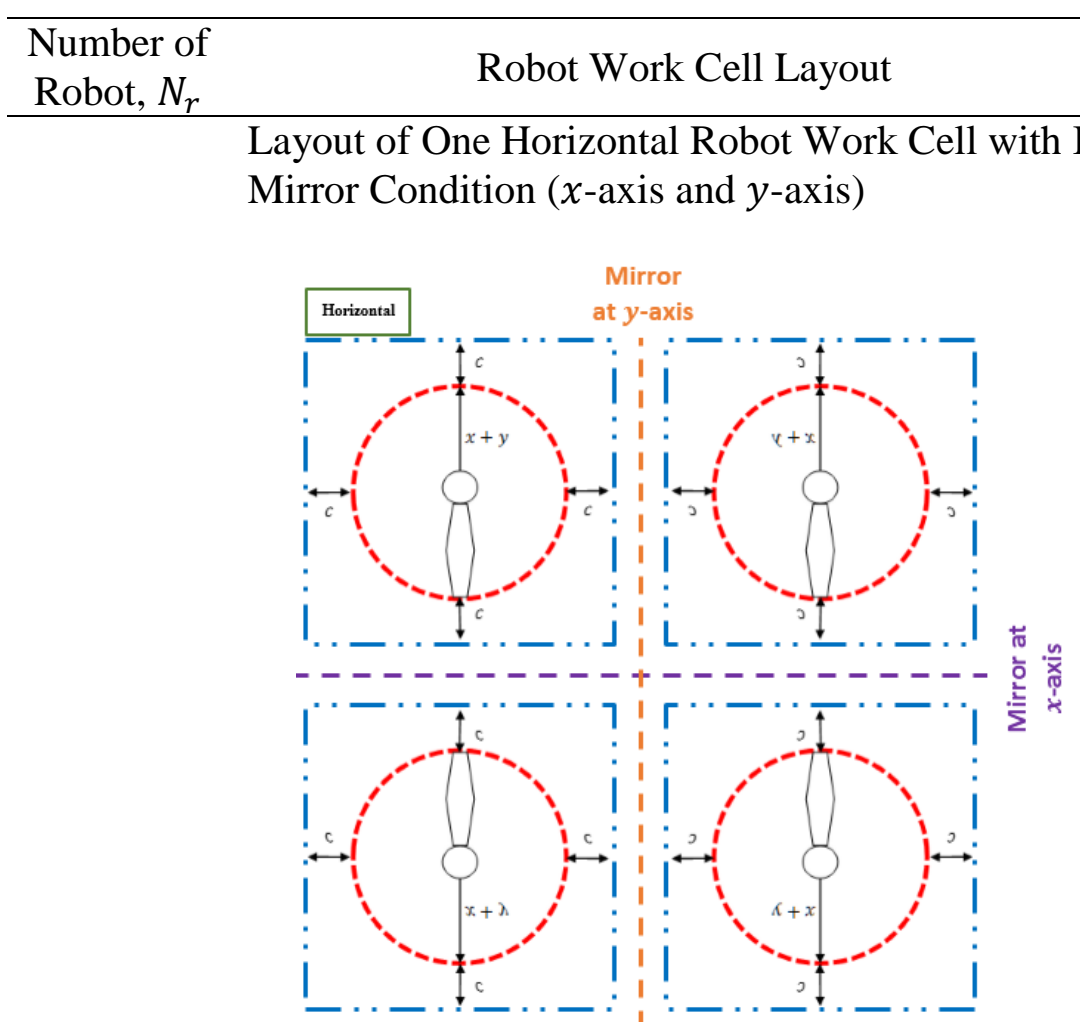

$1 \quad$ Layout of One Vertical Robot Work Cell with Its Mirror Condition ( $x$-axis and $y$-axis)

Total Number of Configuration, $N_{c}$

Layout of One Horizontal Robot Work Cell with Its

Condition ( $x$-axis and

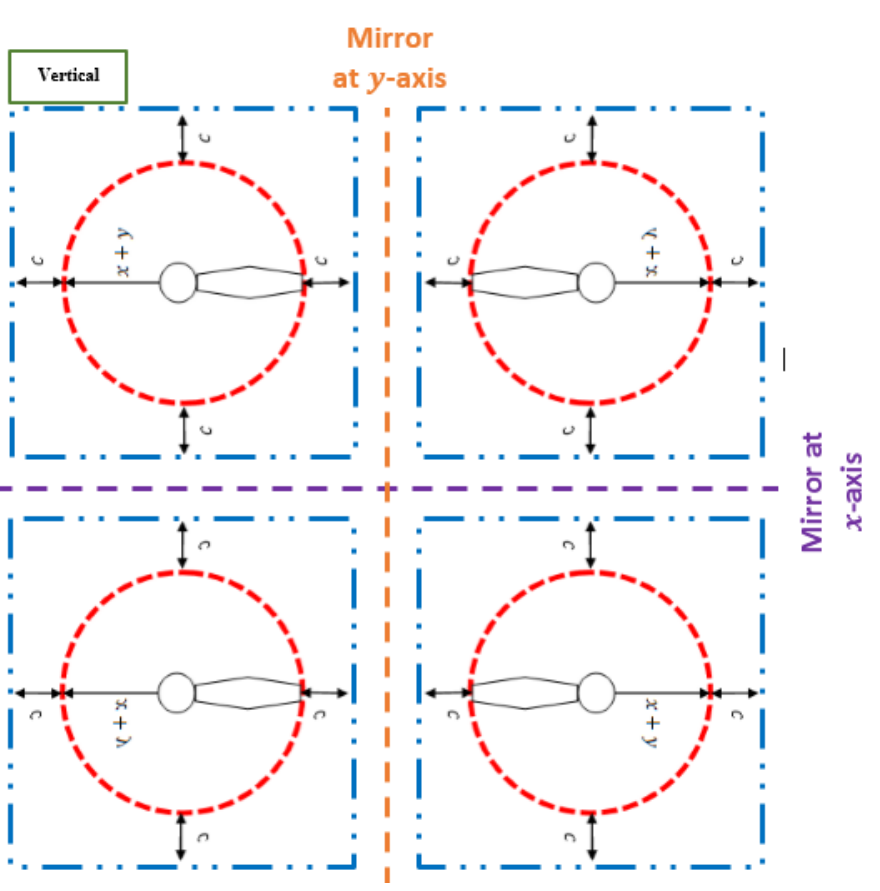


Table 2. Continued

Layout of Two Horizontal Robot Work Cells with Its Mirror Condition ( $x$-axis and $y$-axis)

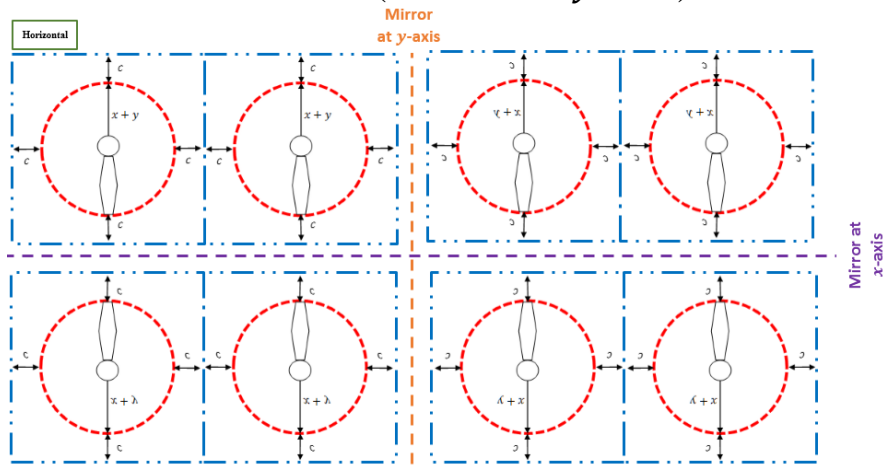

Layout of Two Vertical Robot Work Cells with Its Mirror Condition ( $x$-axis and $y$-axis)

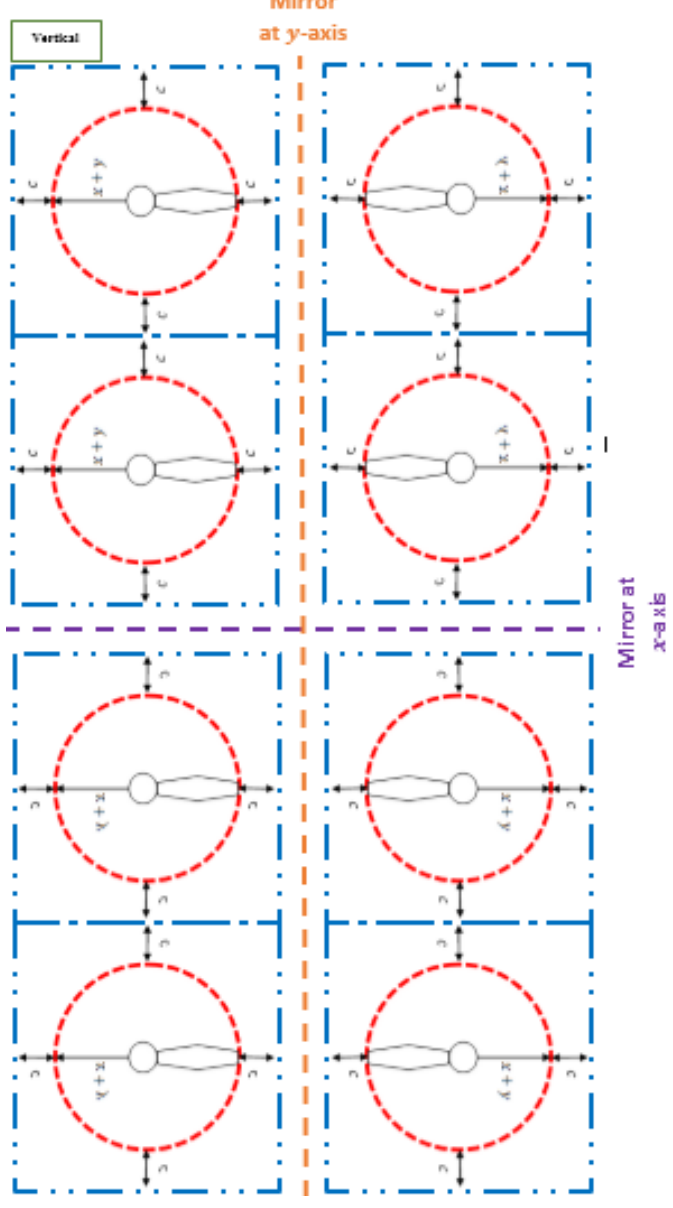

B. Condition 2: Configuration without Dual and with Mirror Condition, $C_{2}$ 
Table 3. Multi-Shape Designed Layout with Condition 2

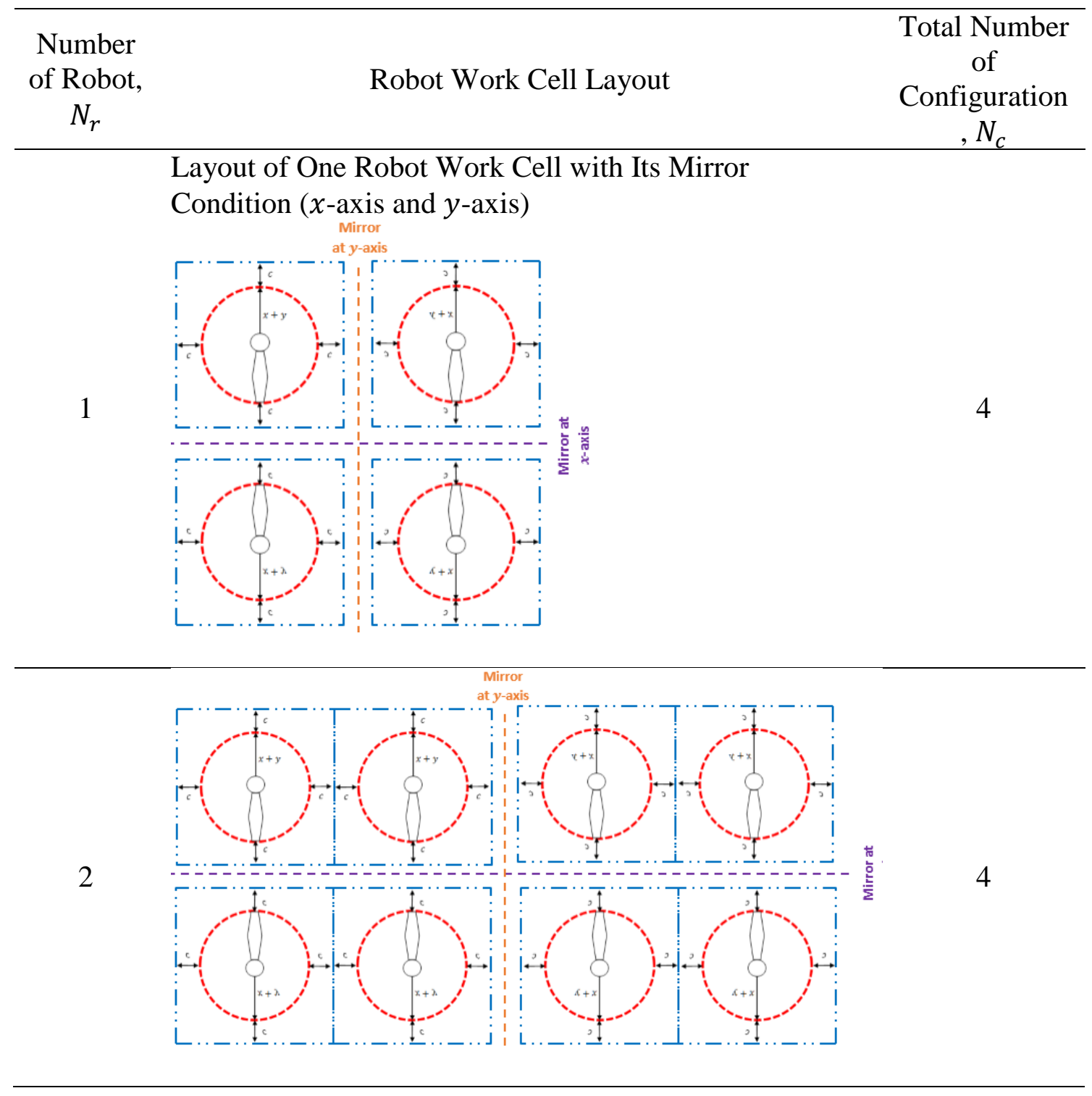

Table 3 illustrates the linear arrangement of robot work cell layouts for the without dual but with mirror condition configuration. The robot work cell layout was developed for the mirror condition using both the $x$-axis and $y$-axis in the same figure. From the above figure, it can be concluded that the usage of one robot is possible to create another four robot work cell layouts, while when using two robots, it is also possible to create another four layouts using the mirror condition. 
C. Condition 3: Configuration without Dual and with Mirror Condition, $C_{3}$

Table 4. Multi-Shape Designed Layout with Condition 3

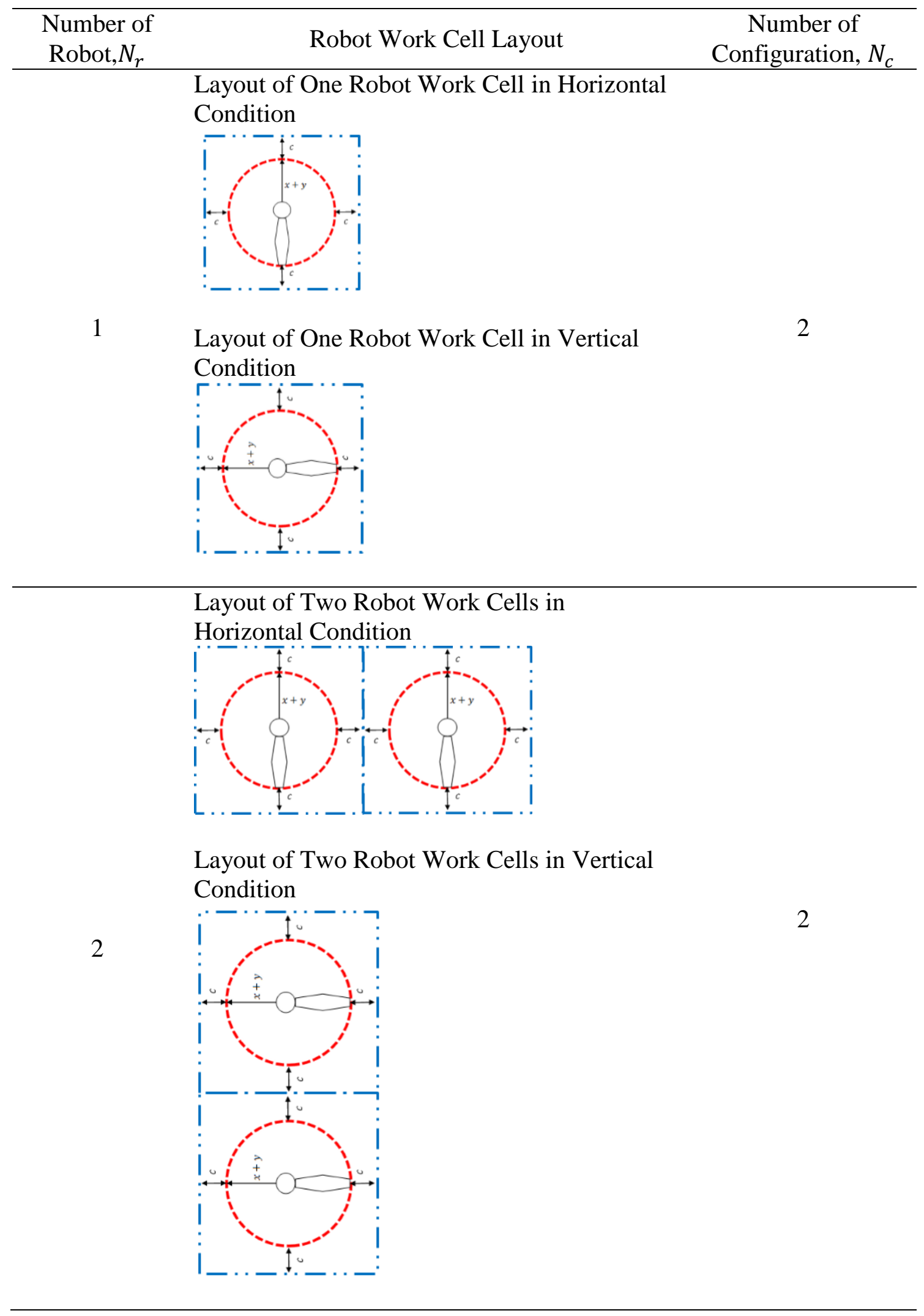


Table 4 illustrates the linear arrangement of the robot work cell layout under the dual condition configuration. The robot work cell's layout was developed in the horizontal and vertical positions. The above figure shows that the usage of one robot is possible to create another two robot work cell layouts, while using two robots, it is possible to create another two layouts using the dual condition.

D. Condition 4: Configuration without Both Dual and Mirror Conditions, $C_{4}$

Table 5. Multi-Shape Designed Layout with Condition 4

\begin{tabular}{|c|c|c|}
\hline $\begin{array}{l}\text { Number of Robot, } \\
\qquad N_{r}\end{array}$ & Robot Work Cell Layout & $\begin{array}{l}\text { Number of Configuration, } \\
N_{c}\end{array}$ \\
\hline 1 & & 1 \\
\hline 2 & & 1 \\
\hline
\end{tabular}

Table 5 illustrates the linear arrangement of a robot work cell layout for the configuration of without both dual and mirror conditions. The dual and mirror conditions were selected to be the constraints for this configuration. From the above figure, it shows that the usage of one robot is possible to create a single layout of the robot work cell, and with the use of two robots, it is also possible to create a single layout under these conditions.

Table 6. Robot Work Cell Configuration

Number of Robot Use, $N_{r}$

$\left.\begin{array}{cccccccccccc}\hline \text { Num. } & \begin{array}{c}\text { Configuration } \\ \text { Condition, } C_{n}\end{array} & 1 & 2 & 3 & 4 & 5 & 6 & 7 & 8 & 9 & 10 \\ \hline 1 & C_{1} & 8 & 8 & 16 & 40 & 96 & 280 & 864 & 2952 & 10280 & 37240 \\ 2 & C_{2} & 4 & 4 & 8 & 20 & 48 & 140 & 432 & 1476 & 5140 & 18620 \\ 3 & C_{3} & 2 & 2 & 4 & 10 & 24 & 70 & 216 & 738 & 2570 & 9310 \\ 4 & C_{4} & 1 & 1 & 2 & 5 & 12 & 35 & 108 & 369 & 1285 & 4655\end{array}\right)$


Table 6 represents the data on the possible configurations using ten robots with respect to certain conditions. The complexity of these four configurations was compared. The complex configurations may refer to the behavior of configurations which is intricate and hard to model. By comparing these four configurations, the configuration without dual and mirror conditions was selected as the most optimal because it has the least complicated configuration where identical shapes or arrangements of robot work cell layout were eliminated. The selected configuration condition is highlighted in Table 6 . This theoretical development information may assist design engineers in the initial stages of the design and configuration of robot work cells.

\section{Mathematical Model}

Prior to the development of a multi-shaped layout, a line graph with a mathematical model of the configuration pattern was developed based on the relationship between the number of robots, $N_{r}$ and the number of configurations, $N_{c}$. The configuration pattern is illustrated by using MATLAB. The line graph and mathematical model are illustrated in Figures 6 and 7.

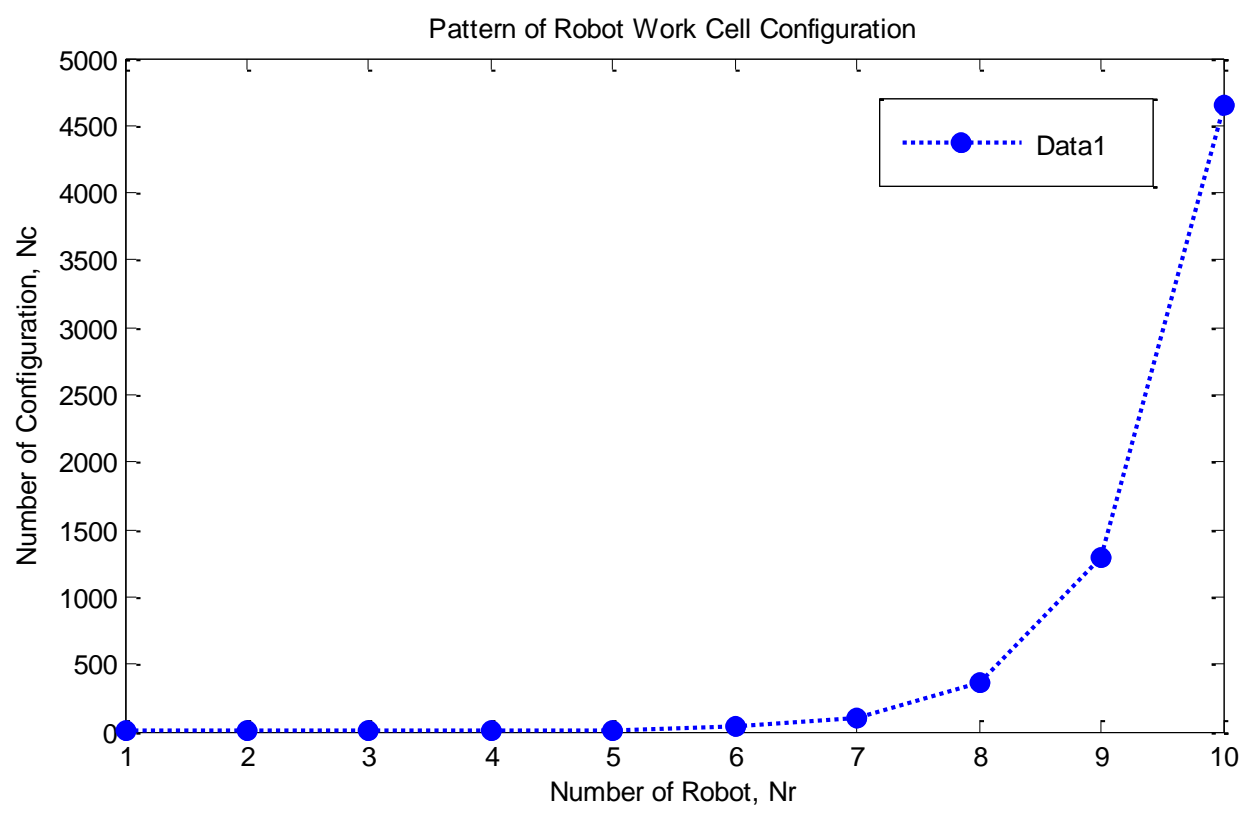

Figure 6. Line Graph of Configuration Pattern

By using the Basic Fitting editor of the $9^{\text {th }}$ polynomial and selecting the centre and scale $x$ data checkbox, another line graph that fits the overlaying data and the residuals was plotted. The 9th polynomial with the centre and scale $x$ data checkbox was used to improve the precision of the computed parameters. The fit of the plotted graph's mathematical model is displayed in Figure 7 by selecting the show equation checkbox. 


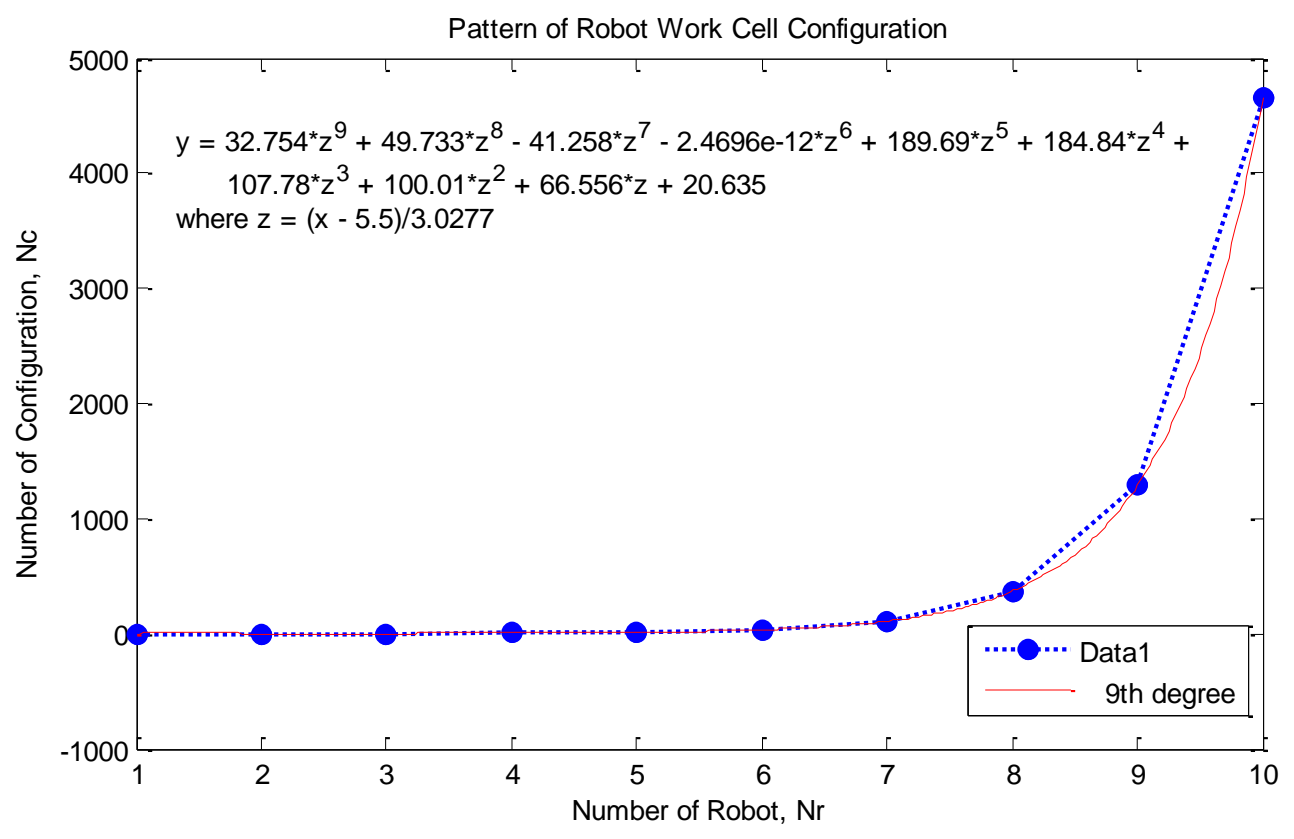

Figure 7. Line Graph of Configuration Pattern with Basic Fitting

From Figure 7, the mathematical relationship extracted is as follows:

$N_{c}=p_{1} z^{9}+p_{2} z^{8}+p_{3} z^{7}+p_{4} z^{6}+p_{5} z^{5}+p_{6} z^{4}+p_{7} z^{3}+p_{8} z^{2}+p_{9} z+p_{10}$

where

Coefficients:

$p_{1}=32.754 ; \quad p_{2}=49.733 ; \quad p_{3}=-41.258 ; \quad p_{4}=-2.4696 e^{-12} ; \quad p_{5}=189.69 ;$

$p_{6}=184.84 ; \quad p_{7}=107.78 ; \quad p_{8}=100.01 ; \quad p_{9}=66.556 ; \quad p_{10}=20.635$

$\mathrm{Z}$ is centred and scaled:

$$
\mathrm{Z}=\frac{\left(\mathrm{N}_{\mathrm{r}}-5.5\right)}{3.0277}
$$

The norm of residuals for the plotted graph is $9.0353 e^{-13}$. A high degree of the polynomial will result in a low norm. A smaller norm will cause over fitting.

Figure 8 illustrates the residual plot of the $9^{t h}$ polynomial graph. Each residual is the difference between an ordinate data value and a corresponding fit value at a specific abscissa value. It is used to measure the goodness of basic fit laying on the actual graph. The proposed mathematical relationship has been evaluated using the same tool by inserting the $\mathrm{N}_{\mathrm{r}}$ to get the $\mathrm{N}_{\mathrm{c}}$. From the evaluation plot in Figure 9, it can be concluded that the evaluation results $(\mathrm{y}=\mathrm{f}(\mathrm{x}))$ meet the actual values (data1) which is the number of configurations, $N_{c}$ for $C_{4}$ presented in the Table 6 . Thus, the proposed mathematical relationship is accepted for this approach. The developed mathematical model can assist in determining the trend of selected configurations of robot work cells and also in predicting the number of configurations for more than ten robots. 


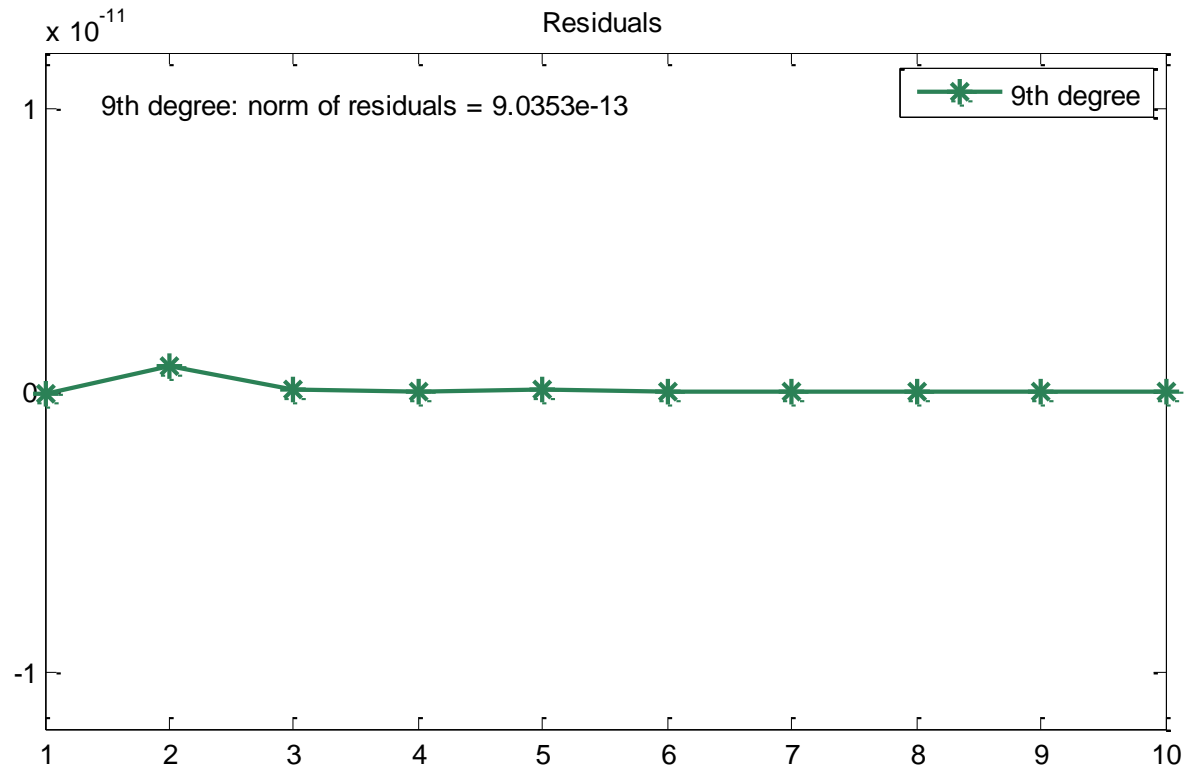

Figure 8. Line Graph of Residuals of Configuration Pattern

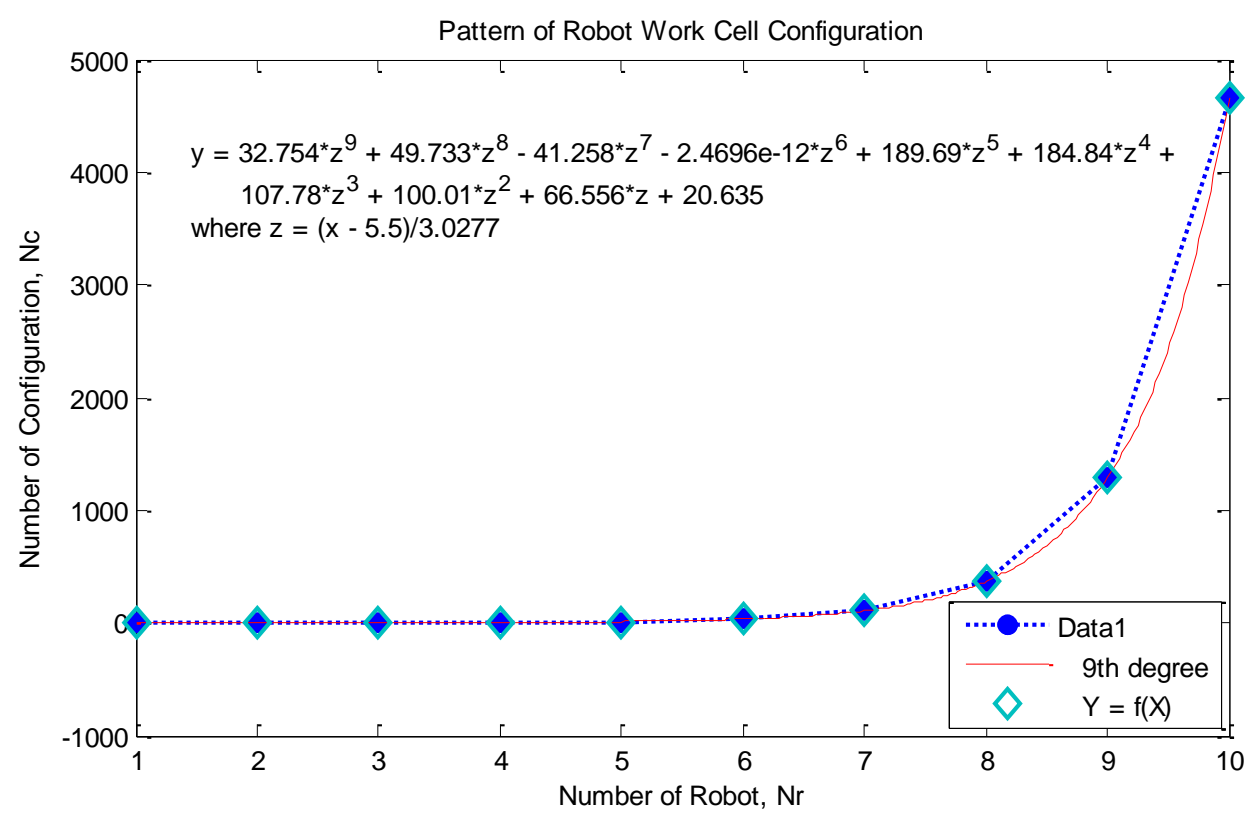

Figure 9. Evaluation Plot, $y=f(x)$

\section{CONCLUSIONS}

In conclusion, this work attempts to give an initial conceptual approach for future work in (re-)configuring multi-robot work cells. This work represents the multi-shaped layout configuration which is developed through joining one or more equal squares side-by-side according to the quantity of robots used. The multi-shaped layout configuration concept was later optimised by eliminating the identical shape or arrangement of the robot work cell layout. This configuration concept involves a simple arrangement condition wherein configurations with the corner, half facing, diagonal and mix arrangement are excluded 
to reduce the complexity of the development. The pattern of the developed configuration and its mathematical relationship between the number of robots and the number of configurations or in other words, the number of variation shapes were successfully extracted using MATLAB. The mathematical relationship produced can support design engineers during the configuration of inline robot work cells, especially in determining the number of possible optimal robot work cell configurations $\mathrm{N}_{\mathrm{c}}$ according to the number of robots, $\mathrm{N}_{\mathrm{r}}$. Nonetheless, further research in platform implementation is needed to further optimise the approach and make it suitable for real applications in the industry.

\section{ACKNOWLEDGEMENT}

This research was supported by grant No. FRGS/1/2017/TK03/FKP-AMC/F00342 from the Fundamental Research Grant Scheme of the Malaysia Ministry of Higher Education. We are also grateful to Universiti Teknikal Malaysia Melaka (UTeM) for funding the research student under MyBrain UTeM and providing materials support and useful information. This work is also a collaborative work with the Department of Occupational Safety \& Healh (DOSH) Malaysia.

\section{REFERENCES}

[1] Koren Y. The global manufacturing revolution: product-process-business integration and reconfigurable systems: John Wiley \& Sons; 2010.

[2] Mohamed N, Khan MK. Decomposition of manufacturing processes: A review. 2012.

[3] Garg H, Singh R. Pattern development for manufacturing applications with fused deposition modelling-a case study. International Journal of Automotive and Mechanical Engineering. 2013;7:981.

[4] Rose A, Deros BM, Ab Rahman MN. A study on lean manufacturing implementation in Malaysian automotive component industry. International Journal of Automotive and Mechanical Engineering. 2013;8:1467.

[5] Wadhwa RS. Flexibility in manufacturing automation: A living lab case study of Norwegian metalcasting SMEs. Journal of Manufacturing Systems. 2012;31:44454.

[6] Lueth TC. Automated planning of robot workcell layouts. Robotics and Automation, 1992 Proceedings, 1992 IEEE International Conference on: IEEE; 1992. p. 1103-8.

[7] Haniff M, Ismail A, Deros BM, Rahman M, Kardigama K. The taguchi approach in optimizing environmental factors affecting productivity in the automotive industry. International Journal of Automotive and Mechanical Engineering. 2011;3:306-17.

[8] Neal R. NGM-Next Generation Manufacturing, A Framework for Action (USA Project). Enterprise Engineering and Integration: Springer; 1997. p. 307-15.

[9] Robotics IIFo. World Robotics 2015 Survey - Executive Summary. 2015.

[10] Bojinov H, Casal A, Hogg T. Multiagent control of self-reconfigurable robots. Artificial Intelligence. 2002;142:99-120.

[11] Koren Y, Hu SJ, Weber TW. Impact of manufacturing system configuration on performance. CIRP Annals. 1998;47:369-72. 
[12] Rahman MAA, Mo JP. Development of theoretical reconfiguration structure for manufacturing automation systems. International Journal of Agile Systems and Management. 2012;5:132-50.

[13] Rahman MAA, Mo JP. Design methodology for manufacturing automation system reconfiguration. ASME 2010 International Mechanical Engineering Congress and Exposition: American Society of Mechanical Engineers; 2010. p. 429-38.

[14] Mastura M, Sapuan S, Mansor M. A framework for prioritizing customer requirements in product design: Incorporation of FAHP with AHP. Journal of Mechanical Engineering and Sciences. 2015;9:1655-70.

[15] Reinhart G. Current state model for easy reconfiguration of robot systems and offline-programming-environments. Robotics (ISR), 2010 41st International Symposium on and 2010 6th German Conference on Robotics (ROBOTIK): VDE; 2010. p. 1-8.

[16] Rahman MAA, Osman NS, Boon CH, Poh GLT, Rahman AAA, Mohamad BMB, et al. Configuring Safe Industrial Robot Work Cell in Manufacturing Industry. Journal of Advanced Manufacturing Technology (JAMT). 2016;10:125-36.

[17] Osman N, Rahman M, Rahman AA, Kamsani S, Mohamad BB, Mohamad E, et al. Development of An Automated Configuration System for Robot Work Cell. Journal of Advanced Manufacturing Technology (JAMT). 2017;11:113-28.

[18] Osman NS, Rahman MAA, Rahman AAA, Kamsani SH, Mohamad E, Mohamad $\mathrm{BMB}$, et al. Configuring robot work cell in manufacturing industry. International Journal of Agile Systems and Management. 2017;10:295-320.

[19] Osman N, Rahman M, Rahman A, Mohamad B, Kamsani S. Optimization of multiple robot configuration pattern using shape variant approach. Innovative Research and Industrial Dialogue. 2017.

[20] Rahman M, Rahman AA, Kamsani S, Mohamad B. Determination of the optimal workspace and manufacturing throughput time for configuring robot work cell. Proceedings of Mechanical Engineering Research Day 2017. 2017;2017:103-4.

[21] Osman N, Rahman M, Rahman AA, Kamsani S, Mohamad BB, Mohamad E, et al. Automated platform for designing multiple robot work cells. IOP Conference Series: Materials Science and Engineering: IOP Publishing; 2017. p. 012061.

[22] Osmana N, Rahmana M, Rahmana AA, Kamsania S, Bali B, Mohamada EM, et al. Systematic Approach in Determining Workspace Area and Manufacturing Throughput Time for Configuring Robot Work Cell. Transdisciplinary Engineering: A Paradigm Shift. 2015:959.

[23] Sarin S, Wilhelm W. Prototype models for two-dimensional layout design of robot systems. IIE Transactions. 1984;16:206-15.

[24] Chedmail P, Wenger P. Design and Positioning of a Robot in an Environment with Obstacles using Optimal Research. Robotics and Automation, 1989 Proceedings, 1989 IEEE International Conference on: IEEE; 1989. p. 1069-74.

[25] Seki M, Tatsumi H. Method of deciding robot layout. Google Patents; 1990.

[26] Tay M, Ngoi B. Optimising robot workcell layout. The International Journal of Advanced Manufacturing Technology. 1996;12:377-85.

[27] Feddema JT. Kinematically optimal robot placement for minimum time coordinated motion. Robotics and Automation, 1996 Proceedings, 1996 IEEE International Conference on: IEEE; 1996. p. 3395-400.

[28] Gueta LB, Chiba R, Arai T, Ueyama T, Ota J. Compact design of work cell with robot arm and positioning table under a task completion time constraint. 
Intelligent Robots and Systems, 2009 IROS 2009 IEEE/RSJ International Conference on: IEEE; 2009. p. 807-13.

[29] Kamrani B, Berbyuk V, Wäppling D, Stickelmann U, Feng X. Optimal robot placement using response surface method. The International Journal of Advanced Manufacturing Technology. 2009;44:201-10.

[30] Tao L, Liu Z. Optimization on multi-robot workcell layout in vertical plane. Information and Automation (ICIA), 2011 IEEE International Conference on: IEEE; 2011. p. 744-9.

[31] Zhang E-D, Qi L-L, Murphy S. Method and system for optimizing the layout of a robot work cell. Google Patents; 2013.

[32] Tao J, Wang P, Qiao H, Tang Z. Facility layouts based on differential evolution algorithm. Robotics and Biomimetics (ROBIO), 2013 IEEE International Conference on: IEEE; 2013. p. 1778-83.

[33] Pellegrinelli S, Pedrocchi N, Tosatti LM, Fischer A, Tolio T. Multi-robot spotwelding cells: An integrated approach to cell design and motion planning. CIRP Annals-Manufacturing Technology. 2014;63:17-20.

[34] Spensieri D, Carlson JS, Bohlin R, Kressin J, Shi J. Optimal robot placement for tasks execution. Procedia CIRP. 2016;44:395-400.

[35] Spensieri D, Bohlin R, Carlson JS. Coordination of robot paths for cycle time minimization. Automation Science and Engineering (CASE), 2013 IEEE International Conference on: IEEE; 2013. p. 522-7.

[36] Asfahl C. Robots and manufacturing automation: John Wiley \& Sons, Inc.; 1992.

[37] Rahman M. Improvement of Safety System Installation for Industrial Robot Work Cell. Universiti Tenaga Nasional. 2005.

[38] Golomb SW. Polyominoes: puzzles, patterns, problems, and packings: Princeton University Press; 1996. 